
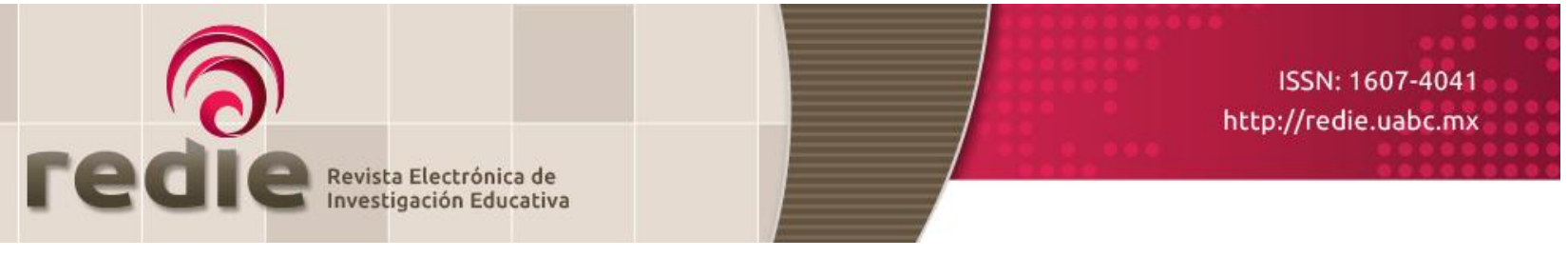

Vol. 22, 2020/01

\title{
Educar al profesor de Historia
}

\author{
Víctor Said Romero Rocha (*) https://orcid.org/0000-0003-1210-0079
}

(*) Benemérita Universidad Autónoma de Puebla

Cómo citar: Romero, V. S. (2020). Educar al profesor de Historia. Revista Electrónica de Investigación Educativa, 22, 01, 1-3. https://doi.org/10.24320/redie.2020.22.e1r.3892

\section{Obra reseñada}

Gómez Bonilla, E. (2018). Educar en competencias. Reflexiones sobre la enseñanza de la Historia. Benemérita Universidad Autónoma de Puebla.

El libro de Gómez Bonilla ${ }^{1}$ debate el dilema de la última década sobre la enseñanza de la Historia en México - persistente en diversos elementos del aprendizaje de los estudiantes de educación secundaria y media superior. Mientras numerosas doctrinas académicas se han actualizado, la Historia ha preservado la misma metodología en su enseñanza, las consecuencias de esto han evidenciado en años recientes que los estudiantes la consideran una disciplina monótona y sin aportes relevantes para su configuración personal.

Educar en competencias. Reflexiones sobre la enseñanza de la Historia describe una serie de métodos didácticos y metodológicos estudiados desde la práctica docente, junto a la divulgación histórica adjunta con la formación crítico-social de los estudiantes. Su intención es renovar los métodos de enseñanza empleada por los profesores de Historia en secundaria y bachillerato.

La publicación se divide en tres capítulos, el primero es un señalamiento a los problemas recientes por medio de la didáctica, relacionados con el contexto mexicano en los últimos años. La realidad del panorama que enfrentan los historiadores en la enseñanza en educación secundaria y media superior. El autor describe algunos ejemplos de alumnos que consideran irrelevante la materia al tiempo que revelan otros aspectos de la misma: la monotonía y la memorización.

El presente mexicano exige a los profesores abordar la "educación basada en competencias", técnica aprovechada en el currículum formativo acorde con los programas de estudio en la educación en México, a fin de buscar la formación de estudiantes con aptitudes en "conocimiento, habilidades y actitudes" por asignatura desempeñada (p. 25). El objetivo es realizar una construcción intelectual, representativa y reflexiva socialmente mediante contribuciones significativas en el aula, para que los jóvenes la pongan en práctica en su cotidianidad.

\footnotetext{
${ }^{1}$ Edgar Gómez Bonilla es investigador en Enseñanza Superior del Posgrado en Educación Superior de la Facultad de Filosofía y Letras de la Benemérita Universidad Autónoma de Puebla (México). Sus líneas de investigación son: procesos de formación y actores de la educación media superior y superior, evaluación del desempeño docente, y planeación e intervenciones didácticas relacionadas con la enseñanza de la Historia.
} 
El constante predicamento en la trayectoria académica de los historiadores durante la licenciatura corresponde al fortalecimiento curricular de habilidades pertenecientes a la investigación científica. Sin embargo, son insuficientes las asignaturas asociadas con la docencia, razón por la cual los egresados de Historia no adquieren las habilidades necesarias para la enseñanza. Ahora bien, carecer de formación en didáctica y pedagogía no debe impedir a los historiadores adentrarse en el campo de la docencia; se deben incluir en su formación estrategias para fortalecer la divulgación de contenidos académicos interesantes tanto en estudiantes como en docentes.

El propósito de investigación de Gómez Bonilla en este primer capítulo se divide en cuatro segmentos (saberes curriculares, saberes didácticos, saberes del entorno y saberes estratégicos) que estructuran la información, facilitan la transmisión cognitiva, fomentan el aprendizaje de los alumnos y logran razonamiento crítico sobre los hechos pasados ejemplificados con el presente (pp. 18-24).

El docente de las asignaturas de Historia Universal e Historia de México está obligado a contextualizar su labor al acontecer actual con ayuda de las competencias didácticas a modo de enseñanza dinámica. La solución, indica el autor, es proponer actividades que generen productos académicos en cada clase, productos que permitirán reforzar la adquisición de saberes históricos y "discutir sobre el presente a través de la construcción del pasado histórico" (p. 32).

El planteamiento de Gómez Bonilla retoma condicionantes notables en los profesores con el objetivo de alcanzar la apreciación de situaciones históricas en sus estudiantes. Hay que mencionar, además, la implementación de las competencias para la vida, como son "la organización y proyección del saber histórico con iniciativa, innovación en el discurso histórico y resolución con iniciativa histórica" (p. 33). Las competencias para la vida buscan fomentar en los estudiantes el entusiasmo por aprender Historia, en relación con el interés del docente por proporcionar una enseñanza satisfactoria.

La posición del maestro de Historia dentro del aula está sujeta a la neutralidad con la intención de lograr una sana convivencia y respeto entre ambas partes, principal propósito de la participación dentro del aula. Esta interacción entre el docente y los alumnos evidencia el interés de los jóvenes al exponer sus opiniones respecto a la temática discutida en la clase.

El segundo capítulo explica la construcción sistemática y metodológica desde la postura de las competencias educativas. Gómez Bonilla señala cuestiones que aluden a los principios sociales, valores y actitudes hacia sucesos novedosos, distanciándose de los viejos modelos pedagógicos que se basan en la enseñanza clásica de la denominada "Historia de Bronce". El autor sugiere diseñar una nueva metodología, acorde con las corrientes historiográficas: historia social, cultural, vida cotidiana, tiempo presente, giro lingüístico, etcétera, donde el instructor tenga la libertad de utilizar los conocimientos teóricos obtenidos en la universidad.

Cabe mencionar que México se encuentra en la inexorable revolución digital, situación que genera fastidio en los alumnos hacia los métodos de enseñanza tradicionales, ante esto, Gómez Bonilla sugiere el uso de herramientas tecnológicas como soporte didáctico. La profesionalización de los educadores no se limita a eventos históricos, señala, sino a innovar con "modelos pedagógicos, tecnologías de enseñanza y metodologías docentes" (pp. 39-76). Tanto las Tecnologías de la Comunicación (TIC) como las metodologías de la enseñanza incentivan la construcción de una forma de interactuar más recreativa.

El avance de las tic y la actualización de las metodologías de enseñanza obligan a los historiadores a ser consistentes en la modernización de las temáticas y en el manejo de herramientas didácticas, tales como videos, aplicaciones digitales, películas, videojuegos, historietas, juegos de mesa, programas de televisión, novelas gráficas y demás, herramientas que transforman las clases en una actividad divertida,donde el profesor progresa en sus estilos de enseñanza y el estudiante comprende los hechos históricos. 
El apartado dos hace énfasis también en la pedagogía constructivista de Vygotsky (1934) y la Teoría del aprendizaje significativo de Ausubel (1968). Gómez Bonilla describe ejemplos de modelos de impartición en sesiones de Historia de México; en el aula, el docente es partícipe de la reinterpretación en dinámicas vinculadas con el alcance del objetivo, este objetivo se comprueba con un producto académico realizado por los estudiantes durante la sesión. Esta evidencia tangible demuestra el propósito de la asignatura y cambia, según la meta a conseguir, durante cada lección. Algunos ejemplos de productos académicos citados por Gómez Bonilla son: reseñas de libros, resúmenes, críticas y reflexiones escritas, dibujos, elaboración de mapas o videoblogs.

El capítulo tres sistematiza los elementos descritos en los dos primeros. El autor divide esta parte del libro en cuatro aspectos, los cuales buscan mejorar las jornadas de los docentes. Las denominadas "gestiones" son una jerarquización de problemáticas didácticas, asociadas a las dificultades existentes en el aula, instituciones y programas. Al mismo tiempo, se vincula la interacción entre alumnos, académicos, directivos y padres de familia en el siguiente orden: educativa, institucional, escolar y pedagógica (pp. 69-77).

La "gestión educativa" engloba los programas establecidos por la Secretaría de Educación Pública (SEP) para la impartición de las clases de Historia; la "gestión institucional" analiza los asuntos educativos permitidos dentro de la institución correspondiente del educador; la "gestión escolar" es el espacio académico-laboral entre el personal de la escuela, directivos, padres de familia u otras figuras de autoridad; y la "gestión pedagógica" comprende la relación profesor-alumnos, evidenciada en el dominio de temas de estudio, métodos pedagógicos y organización de las clases a partir de la elaboración de diferentes planes de clase (pp. 67-81).

El capítulo expone algunos elementos a considerar en la construcción del "plan de clase", desde la organización del tema, objetivo principal, distribución del tiempo, actividad en clase, instrumentos didácticos, reflexiones, conclusiones y obtención de un producto final realizado por el estudiante. En algunas ocasiones se pueden solicitar actividades extraclase, las cuales complementan aspectos relacionados con la temática analizada. Asimismo, se representan los conocimientos del docente, teorías y corrientes historiográficas, simplificados a criterio del estudiante. El educador es libre de incorporar o cambiar los temas de clase en conjunto con los lineamientos establecidos por la SEP o la institución en la que labore.

El libro muestra una visión acertada del oficio de los profesores de Historia y la corrección de errores en el terreno laboral. La publicación es un exhorto a mejorar las destrezas de enseñanza en clase y fortalecer el desempeño crítico-analítico en los alumnos.

Sin embargo, aunque el libro brinda ejemplos específicos sobre Historia de México no aborda la enseñanza de la Historia Universal, y sería interesante la construcción de planes de clase con temas internacionales. Por otro lado, las herramientas didácticas están enfocadas a las secundarias y bachilleratos urbanos, sin dar ejemplos para las escuelas rurales; no obstante, la información, estructura, serialización y desarrollo de contenidos en la obra son muy útiles para enmendar los errores más comunes que se cometen en el aula.

En conclusión, el aporte de Gómez Bonilla evidencia las problemáticas comunes en los profesores de Historia, sin embargo profesores de otras asignaturas pueden aprovecharlo en sus respectivas disciplinas. 